\title{
Merits of collaboration between industry and academia
}

\author{
Charlotte E L Evans lecturer in nutritional epidemiology ${ }^{1}$, Darren Greenwood senior lecturer in \\ biostatistics ${ }^{2}$, Victoria Burley senior lecturer in nutritional epidemiology ${ }^{1}$, Janet Cade professor in \\ nutritional epidemiology ${ }^{1}$
}

${ }^{1}$ Nutritional Epidemiology Group, School of Food Science and Nutrition, University of Leeds, Leeds LS2 9JT, UK; ${ }^{2}$ Centre for Epidemiology and Biostatistics, University of Leeds, Leeds, UK

As a group of scientists working within academia, we are concerned by the implications of your feature suggesting that industry should stop funding external research. ${ }^{1}$ Universities are one of the best types of institution to carry out nutrition research because academic researchers are interested in finding out the truth. Would it be better if all universities refused to work with the food industry and the food industry carried out its own research without collaboration with universities? We think not. It would lead to inferior research, greater potential for bias, and the decision to publish resting with the sponsor, potentially increasing publication bias.

Most journals have clear guidelines for declaring potential competing interests. ${ }^{2}$ The guidelines specify that the funding body should have no role in the study design, analysis of the data, or content of the publication. Even freelance journalists commissioned by The BMJ declare their many competing interests. Yet it is this transparency that forms the basis of the article's criticisms.

In addition to singling out individuals for criticism, simply because they follow best practice in declaring competing interests, this article targeted the carbohydrates working group of the government's Scientific Advisory Committee on Nutrition (SACN). It failed to mention that the SACN committee commissioned its own independent research on carbohydrate and cardio-metabolic health, conducted by the University of Leeds, to inform its recommendations. As independent researchers we published our own separate findings and subjected them to further peer review in leading medical journals, including The BMJ. ${ }^{3}$ The committee comprises some of the most active and competent researchers in nutrition research, and it is unlikely that anyone at this senior level would not have some form of competing interest to declare.

Competing interests: CELE has worked on government funded projects as well as projects funded by the Medical Research Council (MRC), Kelloggs, Warburtons, and Kids Company charity. DG has worked on projects funded by government, MRC, World Cancer Research Fund (WCRF), Kelloggs, Meat and Livestock Commission, and Danone. VB has worked on projects funded by government, WCRF, MRC, Kelloggs, Meat and Livestock Commission, and the Sugar Bureau. JC is registrar for the Association for Nutrition and has worked on government funded projects as well as those funded by the MRC, WCRF, National Prevention Research Initiative, Kelloggs, Meat and Livestock Commission, and the Kids Company charity.

Full response at: www.bmj.com/content/350/bmj.h231/rr-5.

1 Gornall J. Sugar: spinning a web of influence. BMJ 2015;350:h231. (11 February.)

2 International Society for Medical Publication Professionals. GPP2 guidelines 2009. www. ismpp.org/gpp2.

3 Threapleton DE, Greenwood DC, Evans CE, Cleghorn CL, Nykjaer C, Woodhead C, et al. Dietary fibre intake and risk of cardiovascular disease: systematic review and meta-analysis. BMJ 2013;347:f6879.

Cite this as: BMJ 2015;350:h1138

๑ B BMJ Publishing Group Ltd 2015 